warning sign of precancer, its prognostic value would have to be established over a longer period that that covered by the studies hitherto reported, for there is evidence that squamous and undifferentiated cancers may originate 10 years or more before death. ${ }^{8} 9$

Even if the early warning value of a cough were established it could help to prevent but a small proportion of cancers. Only half the cancers in the study of Boucot and colleagues occurred in coughers and only half of these may still have been premalignant when the cough began. Experience in antismoking clinics, attended by men who are specially keen to stop smoking, shows an average success rate of about $30 \%{ }^{10}$ Combining these percentages suggests that less than $10 \%$ of lung cancer could at present be prevented by trying to get coughing smokers to stop smoking. But this would not be the only benefit. A smoker's cough is an almost invariable preliminary to disabling bronchitis. If smokers who cough could be persuaded to stop smoking, disability and mortality from chronic bronchitis would certainly be diminished.

The practical problem of persuading people to stop remains the chief obstacle. We need more research into tobacco habituation to discover how more people may be freed from it. Meanwhile doctors should urge all their patients who have a cough to stop smoking forthwith. Only too often they are told to "cut down," and this is practically never possible.

\section{Safety of Halothane}

In most British hospitals halothane is now much the commonest vapour added to the gaseous anaesthetic mixture. But for some years a doubt has attended its administration. Is there a causal connexion between the drug and the post-operative jaundice and fatal hepatic necrosis that have occasionally followed anaesthesia with it?

The sporadic nature of the cases, the non-specific histological appearances of the liver, the presence of other possible causes, and the absence of clear animal experimental evidence of the hepato-toxicity of halothane in the circumstances of anaesthesia have kept this problem open. An obvious method of settling the answer is a prospective study. Apart from its magnitude such an investigation would not be too difficult to organize. However, opinions already expressed about the toxicity of halothane could present anaesthetists with an ethical dilemma, and plans for one large-scale prospective study in the U.S.A. were abandoned on these grounds. Anxieties were considerably allayed by the detailed and comprehensive retrospective studies by W. W. Mushin and colleagues $^{1}$ and E. M. Slater and colleagues ${ }^{2}$ in 1964 . These reports concluded that halothane was no more toxic to the liver than other anaesthetics. A further and very large retrospective study, called the National Halothane Study, was mounted in the United States, with results being analysed from 34 hospitals over a period of four years, and a summary of the report has recently been published. ${ }^{3}$

The important facts exposed by this study are the hospital mortality within six weeks after operation and the incidence

\footnotetext{
1 Mushin, W. W., Rosen, M., Bowen, D. J., and Campbell, H., Brit. med. F., 1964, 2, 329.

slater, E. M., Gibson, J. M., Dykes, M. H. M., and Walzer, S. G., New Engl. F. Med., 1964, 270, 983.

s Summary of the National Halothane Study, f. Amer. med. Ass., 1966, 197,775 .
}

of fatal hepatic necrosis. The study covered 856,000 patients, of whom 82 developed liver necrosis, or about 1 per 10,000 patients. Histological sections and clinical records were examined and a diagnosis made without knowledge of the details of the anaesthetic administered. The total death rate within six weeks of operation was found to be under $2 \%$, but the death rate after administration of halothane was lower than this figure, and was midway among the rates for the several general anaesthetics used. The rate of fatal hepatic necrosis after halothane was lower than that after cyclopropane. The study by Mushin and colleagues ${ }^{1}$ did not show any increased liver damage when halothane was administered to patients with disease of the biliary tract. The present American study reports the same finding. Hepatic necrosis occurred after about 1 in 5,000 cases of cholecystectomy. However, in only one out of the six of these cases did it follow halothane anaesthesia, in spite of the fact that halothane was administered to one-third of the patients having biliary-tract operations.

There were in the American survey a few cases of hepatic necrosis-9 out of the 82-which could not be explained in any way other than by the nature of the anaesthetic. Seven of these patients had received halothane, and five of them had had one or more previous operations within the preceding six weeks. It seems, therefore, that if there is a connexion between halothane and liver damage-and the matter is still open-it is rare, but it might have some connexion with repeated administration of the anaesthetic.

The results of the American study, therefore, support in broad outline those obtained by Mushin and colleagues. It does not establish any causal relationship between halothane and hepatic necrosis, though it does not completely exclude the possibility. It gives the reasonable advice that, until the matter is finally settled, unexplained fever and jaundice in a patient after administration of halothane should contraindicate the subsequent use of the anaesthetic for that patient. Perhaps the most valuable outcome of this impressively large survey is a recommendation which is not directly concerned with halothane-namely, that mortality after surgery and anaesthesia should be looked at again, particularly with regard to any differences between institutions as well as between the various anaesthetics.

\section{Walking Through Angina}

The pain of ischaemic heart disease is one of the most common and most varied of visceral pains. It is usually precipitated by muscular exercise, but some patients get pain only after taking a heavy meal or exposure to cold, and a few others have attacks brought on by smoking. Once the pain has begun during exercise most sufferers find that it persists as long as they continue, and either the pain itself or fear of the consequences of carrying on often causes them to halt.

A few patients find that their pain wears off if they continue to exercise. The earliest known reference to this is in a letter read by William Heberden ${ }^{1}$ at the College of Physicians in London on 17 November 1772. Heberden had just published his account of angina pectoris in the second volume of the Medical Transactions of the College and had received

\footnotetext{
1 Heberden, W., Medical Transactions of the College of Physicians, Vol. 3, p. 1785. London.

${ }^{2}$ MacAlpin, R. N., and Kattus, A. A., Circulation, 1966, 33, 183.
} 
an anonymous letter, no doubt from a medical colleague, describing his own symptoms. The writer, a man aged 52, described typical anginal pain and went on to say :

"I have frequently, when in company, borne the pain, and continued my pace without indulging it, at which times it has lasted from five to perhaps ten minutes, and then gone off as well as I can recollect, rather suddenly, as it came on, than lessening gradually."

The writer concluded his letter by saying that he had directed that an account of his death and permission for a necropsy should be sent to Heberden. Only three weeks after dispatching this letter the writer fell ill while out walking after dinner and died within half an hour. Heberden arranged for a necropsy to be carried out by John Hunter, who found that the left ventricle was thickened and empty of blood. No cause of death, or of the preceding angina, was found.

A number of other writers have described patients possessing this striking ability to overcome their pain by walking through it. A similar phenomenon among patients who suffer intermittent claudication is better known. A recent report by R. N. MacAlpin and A. A. Kattus ${ }^{2}$ from Los Angeles describes 12 patients who were able to overcome angina by continuing to exercise. The pain these patients experienced was of a mild or moderate severity and none had attacks at rest. Typically the pain began after a few minutes walking at two or three miles an hour on a treadmill and after absut 10 minutes began to lessen in severity. The pain continued to improve with exercise at the same rate, and after about half an hour some patients were free of pain and others noted that it was much less severe. During the period when the pain was wearing off the blood-pressure and pulse rate were steady. Some of the patients also seemed to be able to "walk through" ischaemic changes in the electrocardiogram. At the beginning of exercise the ST changes became more severe, but in one or two of those who experienced relief during exercise the electrocardiogram improved at the same time. Others, however, were relieved of their pain at a time when the electrocardiogram was unchanged. Coronary arteriograms were carried out on eight of the patients, and two patterns were observed. Five had occlusion of major coronary channels with good collateral circulation around the obstruction, and three had stenotic lesions in major coronary vessels with no discernible collateral development. MacAlpin and Kattus postulate that a slow dilatation of coronary vessels in response to myocardial hypoxia was responsible for the relief of symptoms. An objection to this hypothesis is that it scarcely explains why several minutes of ischaemic pain are necessary for such dilatation to take place.

There is increasing interest in the possibility of using physical training as a treatment for patients who are troubled by angina on moderate exercise. Some patients with very severe limitation of their exercise capacity are able to achieve substantial improvement after a graded programme of increasing physical activity spread over a period of several months. MacAlpin and Kattus felt that patients who were able to walk through their angina were particularly likely to benefit from a programme of this kind. Improvement in performance after training is, however, not necessarily the result of improved myocardial blood flow through collateral vessels. The results may be explained equally well if the patients develop increased efficiency in the use of their muscles, and so reduce the energy expenditure required for the task.

Careful use of graded exercise may be helpful in finding patients with ischaemic heart disease who may benefit from physical training. The problem should be approached with care, as most physicians have known patients who suffered a myocardial infarction after a period of unusually heavy effort. No patient should be tested to the limit of his endurance by a sudden increase in physical activity. The lesson of Heberden's anonymous correspondent who did not indulge his pain but nevertheless died while out walking is worth remembering.

\section{Medical Teachers}

There are about 2,000 doctors in Britain who are full-time university teachers; and upon them depends the quality of the profession in the future. For some years now recruitment to these posts has been getting more difficult, and successive Governments have been asked to help. They have done nothing. Meanwhile the Minister of Health has promised an expansion of medical schools and an increased output of doctors. Medicai teachers know that any expansion under existing conditions would result in lowering of standards.

At a meeting of the B.iM.A.'s Full-time Medical Teachers and Research Workers Committee on 7 October (Supplement, p. 155) professors and heads of departments spoke of their own experiences. Ten years ago appointments to university departments were made in the grade of assistant lecturer, with three years' probation. Now candidates of adequate calibre could be attracted only by an offer of immediate appointment to a substantive post of lecturer ; and often they had only two to three years' experience in the specialty.

We recently stated (27 August, p. 483) that the Government's failure to admit to a commitment to increase the pay of clinical teachers as a direct consequence of increases in pay to N.H.S. staff was likely to prove a costly error. Since then the situation has worsened. The Association of University Teachers (the A.U.T.), the only body with a right of access to the University Grants Committee on matters of pay for university teachers, has dissolved its medical salaries subcommittee and recommended to the Committee of Vice Chancellors-in effect the employers-and to the U.G.C. that no pay increase should be made to clinical teachers. This is in line with the policy of the A.U.T. that there should be no differential between medical teachers and other university teachers. The B.M.A. was not informed of these decisions. Its Full-time Teachers Committee's reaction, not surprisingly, has been to express no confidence in the ability of the A.U.T. to represent the interests of medical teachers.

The B.M.A. is to send a questionary to all medical teachers asking for their intentions should the Government remain obdurate. It seems likely that many will want either to emigrate or to seek posts in the hospital service, where they would be much better paid. More than most other doctors, medical teachers have remained aloof from medical politics. Few are members of the B.M.A. or the A.U.T. They tend therefore to feel isolated and powerless. Perhaps for this kind of reason a group of younger teachers called a meeting on 13 October, after this journal had gone to press, of representatives of all universities and medical schools to consider setting up an association of medical teachers independent of the B.M.A.

In the medical faculties themselves there is thought already to be some decline in the number and quality of recruits. 